\title{
Editorial: Transport in Plant Microbe Interactions
}

\author{
Pierre-Emmanuel Courty ${ }^{1 *}$ and Daniel Wipf ${ }^{2 *}$ \\ ${ }^{1}$ Department of Biology, University of Fribourg, Fribourg, Switzerland, ${ }^{2}$ UMR 1347 Agroécologie, BP 86510, Centre National \\ de la Recherche Scientifique, Institut National de la Recherche Agronomique, University of Bourgogne Franche-Comté, Dijon, \\ France
}

Keywords: transportome, transport, plant-microbe interactions, membrane transport proteins, membrane

\section{The Editorial on the Research Topic}

\section{Transport in Plant Microbe Interactions}

Plant-microbe interactions are omnipresent in terrestrial ecosystems and central to understand processes of individual growth, community assembly, and biogeochemical cycling. Plants and microbes interact above and below ground, and such interactions could theoretically include all combinations of positive (i.e., mycorrhizal and legume-rhizobia), negative (i.e., pathogenic interactions), or neutral effects. Many plant pathogenic and symbiotic microbes produce specialized structures that invade plant cells, but remain enveloped by plant-derived membranes. These intimate contacts between plant and microbial structures drive either bidirectional flows of nutrients as symbiotic (mycorrhizal or legume-rhizobia) or unidirectional flows as in pathogenic interactions. Whatever the biotrophic context (symbiotic vs. pathogenic), nutrients must pass several membrane barriers and the apoplastic interface before their assimilation by plant or microbial cells. Plant and microbial cells must be "re-programmed," which includes differentiation and polarization of membrane transport functions to take up, to transfer or to exchange nutrients between partners of the biotrophic interaction. However, the mechanisms underlying the functioning and the dynamics of the transportome (the range of genes of an organism that encode proteins contributing to transport molecules across cellular membranes: membrane transporters, ions exchangers, and ion channels) at the biotrophic interface are still poorly understood. The transportome is a key player in nutrient uptake and exchange mechanisms and its regulation pattern is essential in determining the outcome of plant fungal interactions and in adapting to environmental changes.

Availability, uptake, and exchange of nutrients in biotrophic interactions will drive plant growth and modulate biomass allocation, that are central to plant yield, a major outcome, in the context of high biomass production. In a long term approach, unraveling those biotrophic transportomes and their underlying mechanism will be extremely useful in (i) the prediction of plant-microbes ecological niches, (ii) plant diagnosis (i.e., health, nutritional status), (iii) our understanding of microbial ecology and evolution of function, (iv) the development and implementation of environmentally and sustainably agro-ecosystems for crop production, (v) the identification of natural routes to the cycling and sequestration of carbon in terrestrial environments, and (vi) the ecosystem response to climate change (i.e., Schroeder et al., 2013; Gerlach et al., 2015; Larsen et al., 2015; Lemanceau et al., 2015).

Comparative genomics revealed that plants and microbes have a variable repertoire of transporters (Ward et al., 2009; Kohler et al., 2015). In prokaryotes, organisms with larger genomes have been shown to have proportionally more transporters (Paulsen et al., 2000; 
Markowitz et al., 2012). The question of number of microbial transporters functioning at the biotrophic interface is of central interest. This number could be related either to (i) a strong host dependency, (ii) a reduced host dependency if the genome complexity increased, or (iii) a broad plant range with which they interact. The nutritional/trophic transportome puzzle at the biotrophic interface is still far from complete and major pieces such as (i) the system of cellular efflux are still missing, (ii) the functional regulation within microbial species is a black box, (iii) the regulation of nutrient exchanges between organisms is still poorly understood, (iv) the knowledge on the alteration/reorganization of the traffic of vesicular membranes in both partners is on infancy (i.e., Leborgne-Castel and Bouhidel), and (v) also the metabolic patterns of how plants and microbes interact at the biotrophic interface is unknown, suggesting that the key transporter genes need to be elucidated from model organism. Regarding the availability of plant and microbial genomes, only several transporters involved in biotrophic interactions were characterized: mycorrhizal symbiosis (phosphorus nutrition: Becquer et al. general overview: Casieri et al., 2013; nitrogen nutrition: Courty et al., 2015; phosphorus nutrition: Garcia and Zimmermann), root nodule symbiosis (Clarke et al.), actinorhizal symbiosis (Imanishi et al.), and pathogenic interaction (amino-acid nutrition: Struck). Moreover, only few recent studies are about such characterization: metal transporters (Tamayo et al.), an ammonium transporter (Calabrese et al.), phosphate transporters (Walder et al., 2016), and a dipeptide transporter (Belmondo et al.) in the mutualistic fungus Rhizophagus irregularis forming arbuscular mycorrhizas, an aquaporin (Xu et al., 2015) in the mutualistic fungus Laccaria bicolor forming ectomycorrhizas, a monosaccharide transporter (Schuler et al., 2015) in plant pathogenic fungi Ustilago maydis, phosphate transporters (Walder et al., 2015), monosaccharide transporters (Doidy et al., 2012), and sulfate transporters (Casieri et al., 2012) in mycorrhizal plants and an hexose transporter in plants infected by pathogens (Moore et al., 2015). Effects of nutrient deficiency on the transcriptome of both partners at the biotrophic interface

\section{REFERENCES}

Bonneau, L., Huguet, S., Wipf, D., Pauly, N., and Truong, H. N. (2013). Combined phosphate and nitrogen limitation generates a nutrient stress transcriptome favorable for arbuscular mycorrhizal symbiosis in Medicago truncatula. New Phytol. 199, 188-202. doi: 10.1111/nph.12234

Casieri, L., Ait Lahmidi, N., Doidy, J., Veneault-Fourrey, C., Migeon, A., Bonneau, L., et al. (2013). Biotrophic transportome in mutualistic plant-fungal interactions. Mycorrhiza 23, 597-625. doi: 10.1007/s00572-013-0496-9

Casieri, L., Gallardo, K., and Wipf, D. (2012). Transcriptional response of Medicago truncatula sulphate transporters to arbuscular mycorrhizal symbiosis with and without sulphur stress. Planta 235, 1431-1447. doi: 10.1007/s00425-01 2-1645-7

Correa, A., Cruz, C., and Ferrol, N. (2015). Nitrogen and carbon/nitrogen dynamics in arbuscular mycorrhiza: the great unknown. Mycorrhiza 25, 499-515. doi: 10.1007/s00572-015-0627-6

Courty, P. E., Smith, P., Koegel, S., Redecker, D., and Wipf, D. (2015). Inorganic nitrogen uptake and transport in beneficial plant root-microbe interactions. Crit. Rev. Plant Sci. 34, 4-16. doi: 10.1080/07352689.2014.897897 are poorly characterized (Bonneau et al., 2013; Wipf et al.). Increasing applications and improvements of methodologies could complete classical transporter characterization and give a better detection and resolution of the functioning of biotrophic interfaces: transcripts and proteins by laser capture microdissection technology (Koegel et al., 2013), nutrients by NanoSIMS (Kaiser et al., 2015), and metabolites by liquid/gas chromatography-mass spectrometry (Gaude et al., 2015; Rivero et al.). These recent technological achievements in model plants associated to microbial consortia will facilitate comprehensive identification of the key nutrient transporters involved in biotrophic (mutualistic and pathogenic) interactions. The functioning of some of these transporters (i.e., phosphate transporter) could be evolutionary linked in plant-mutualistic (Delaux et al., 2013) and plant-pathogen (Wirthmueller et al., 2013) interactions.

Beside the biotrophic interactions, we should also consider interactions between microbes and their environment (rhizosphere, phyllosphere) that could influence microbial nutritional/trophic transportome. Soils, minerals, and leaves represent specific microbial habitats influencing and controlling the establishment of microbial communities, but also the expression of transport-related genes (Johnson, 2010; Correa et al., 2015; Uroz et al., 2015).

\section{AUTHOR CONTRIBUTIONS}

PC and DW have co-edited the topic and co-prepared the editorial.

\section{ACKNOWLEDGMENTS}

We would like to thank all the authors for their excellent contributions to this e-book as well as all the reviewers for their timely efforts in judging the manuscripts and for giving their valuable constructive comments. This work was supported by the Conseil Régional de Bourgogne PARI AGREE grant to DW and by the Germaine de Stael program (TRANS-BIO 26510SG).

Delaux, P. M., Séjalon-Delmas, N., Bécard, G., and Ané, J. M. (2013). Evolution of the plant-microbe symbiotic 'toolkit'. Trends Plant Sci. 18, 298-304. doi: 10.1016/j.tplants.2013.01.008.

Doidy, J., van Tuinen, D., Lamotte, O., Corneillat, M., Alcaraz, G., and Wipf, D. (2012). The Medicago truncatula sucrose transporter family: characterization and implication of key members in carbon partitioning towards arbuscular mycorrhizal fungi. Mol. Plant 5, 1346-1358. doi: 10.1093/mp/sss079

Gaude, N., Bortfeld, S., Erban, A., Kopka, J., and Krajinski, F. (2015). Symbiosis dependent accumulation of primary metabolites in arbuscule-containing cells. BMC Plant Biol. 15:234. doi: 10.1186/s12870-015-0601-7

Gerlach, N., Schmitz, J., Polatajko, A., Schlüter, U., Fahnenstich, H., Witt, S., et al. (2015). An integrated functional approach to dissect systemic responses in maize to arbuscular mycorrhizal symbiosis. Plant Cell Environ. 38, 1591-1612. doi: $10.1111 /$ pce. 12508

Johnson, N. (2010). Resource stoichiometry elucidates the structure and function of arbuscular mycorrhizas across scales. New Phytol. 185, 631-647. doi: 10.1111/j.1469-8137.2009.03110

Kaiser, C., Kilburn, M. R., Clode, P. L., Fuchslueger, L., Koranda, M., Cliff, J. B., et al. (2015). Exploring the transfer of recent plant photosynthates to soil 
microbes: mycorrhizal pathway vs direct root exudation. New Phytol. 205, 1537-1551. doi: 10.1111/nph.13138

Koegel, S., Ait Lahmidi, N., Arnould, C., Chatagnier, O., Walder, F., Ineichen, K., et al. (2013). The family of ammonium transporters (AMT) in Sorghum bicolor: two AMT members are induced locally, but not systemically in roots colonized by arbuscular mycorrhizal fungi. New Phytol. 198, 853-865. doi: 10.1111/nph.12199

Kohler, A., Kuo, A., Nagy, L. G., Morin, E., Barry, K. W., Buscot, F., et al. (2015). Convergent losses of decay mechanisms and rapid turnover of symbiosis genes in mycorrhizal mutualists. Nat. Genet. 47, 410-415. doi: 10.1038/ ng. 3223

Larsen, P. E., Collart, F. R., and Dai, Y. (2015). Predicting ecological roles in the rhizosphere using metabolome and transportome modeling. PLoS ONE 10:e0132837. doi: 10.1371/journal.pone.0132837

Lemanceau, P., Maron, P. A., Mazurier, S., Mougel, C., Pivato, B., Plassart, P., et al. (2015). Understanding and managing soil biodiversity: a major challenge in agroecology. Agron. Sustain. Dev. 35, 67-81. doi: 10.1007/s13593-014$0247-0$

Markowitz, V. M., Chen, I. M. A., Palaniappan, K., Chu, K., Szeto, E., Grechkin, Y., et al. (2012). IMG: the integrated microbial genomes database and comparative analysis system. Nucleic Acids Res. 40, D115-D122. doi: 10.1093/nar/ gkr1044

Moore, J. W., Herrera-Foessel, S., Lan, C., Schnippenkoetter, W., Ayliffe, M., Huerta-Espino, J., et al. (2015). A recently evolved hexose transporter variant confers resistance to multiple pathogens in wheat. Nat. Genet. 47, 1494-1498. doi: 10.1038/ng.3439

Paulsen, I. T., Nguyen, L., Sliwinski, M. K., Rabus, R., and Saier, M. H. Jr. (2000). Microbial genome analyses: comparative transport capabilities in eighteen prokaryotes. J. Mol. Biol. 301, 75-100. doi: 10.1006/jmbi.2000.3961

Schroeder, J. I., Delhaize, E., Frommer, W. B., Guerinot, M. L., Harrison, M. J., Herrera-Estrella, L., et al. (2013). Using membrane transporters to improve crops for sustainable food production. Nature 497, 60-66. doi: 10.1038 /nature11909

Schuler, D., Wahl, R., Wippel, K., Vranes, M., Münsterkötter, M., Sauer, N., et al. (2015). Hxt1, a monosaccharide transporter and sensor required for virulence of the maize pathogen Ustilago maydis. New Phytol. 206, 1086-1100. doi: $10.1111 /$ nph.13314
Uroz, S., Kelly, L. C., Turpault, M. P., Lepleux, C., and Frey-Klett, P. (2015). The mineralosphere concept: mineralogical control of the distribution and function of mineral-associated bacterial communities. Trends Microbiol. 23, 751-762. doi: 10.1016/j.tim.2015.10.004

Walder, F., Boller, T., Wiemken, A., and Courty, P. E. (2016). Regulation of plants' phosphate uptake in common mycorrhizal networks: role of intraradical fungal phosphate transporters. Plant Signal. Behav. 11:e1131372. doi: 10.1080/15592324.2015.1131372

Walder, F., Brulé, D., Koegel, S., Wiemken, A., Boller, T., and Courty, P. E. (2015). Plant phosphorus acquisition in a common mycorrhizal network: regulation of phosphate transporter genes of the Pht1 family in sorghum and flax. New Phytol. 205, 1632-1645. doi: 10.1111/nph.13292

Ward, J. M., Mäser, P., and Schroeder, J. I. (2009). Plant ion channels: gene families, physiology, and functional genomics analysis. Annu. Rev. Physiol. 71, 59-82. doi: 10.1146/annurev.physiol.010908.163204

Wirthmueller, L., Maqbool, A., and Banfield, M. J. (2013). On the front line: structural insights into plant-pathogen interactions. Nat. Rev. Microbiol. 11, 761-776. doi: 10.1038/nrmicro3118

Xu, H., Kemppainen, M., El Kayal, W., Lee, S. H., Pardo, A. G., Cooke, J. E. K., et al. (2015), Overexpression of Laccaria bicolor aquaporin JQ585595 alters root water transport properties in ectomycorrhizal white spruce (Picea glauca) seedlings. New Phytol. 205, 757-770. doi: 10.1111/nph.13098

Conflict of Interest Statement: The authors declare that the research was conducted in the absence of any commercial or financial relationships that could be construed as a potential conflict of interest.

The handling Editor declared a shared affiliation, though no other collaboration, with one of the authors P-EC and states that the process nevertheless met the standards of a fair and objective review.

Copyright (c) 2016 Courty and Wipf. This is an open-access article distributed under the terms of the Creative Commons Attribution License (CC BY). The use, distribution or reproduction in other forums is permitted, provided the original author(s) or licensor are credited and that the original publication in this journal is cited, in accordance with accepted academic practice. No use, distribution or reproduction is permitted which does not comply with these terms. 